Original Research

\title{
Fabrication and characterization of an antibacterial chitosan/silk fibroin electrospun nanofiber loaded with a cationic peptide for wound-dressing application
}

\author{
Sadjad Khosravimelal ${ }^{1} \cdot$ Milad Chizari $^{1} \cdot$ Behrouz Farhadihosseinabadi $^{2} \cdot$ Mehrdad Moosazadeh Moghaddam $^{1}$. \\ Mazaher Gholipourmalekabadi ${ }^{3}$
}

Received: 8 January 2021 / Accepted: 30 May 2021 / Published online: 28 August 2021

(c) The Author(s) 2021

\begin{abstract}
Wound infections are still problematic in many cases and demand new alternatives for current treatment strategies. In recent years, biomaterials-based wound dressings have received much attention due to their potentials and many studies have been performed based on them. Accordingly, in this study, we fabricated and optimized an antibacterial chitosan/silk fibroin (CS/ $\mathrm{SF}$ ) electrospun nanofiber bilayer containing different concentrations of a cationic antimicrobial peptide (AMP) for wound dressing applications. The fabricated CS/SF nanofiber was fully characterized and compared to the electrospun silk fibroin and electrospun chitosan alone in vitro. Then, the release rate of different concentrations of peptide $(16,32$, and $64 \mu \mathrm{g} / \mathrm{ml})$ from peptide-loaded CS/SF nanofiber was investigated. Finally, based on cytotoxic activity, the antibacterial activity of scaffolds containing 16 and $32 \mu \mathrm{g} / \mathrm{ml}$ of the peptide was evaluated against standard and multi-drug resistant strains of Staphylococcus aureus, Escherichia coli, and Pseudomonas aeruginosa isolated from burn patients. The peptide-loaded CS/ SF nanofiber displayed appropriate mechanical properties, high water uptake, suitable biodegradation rate, a controlled release without cytotoxicity on Hu02 human foreskin fibroblast cells at the 16 and $32 \mu \mathrm{g} / \mathrm{ml}$ concentrations of peptide. The optimized CS/SF containing $32 \mu \mathrm{g} / \mathrm{ml}$ peptide showed strong antibacterial activity against all experimental strains from standard to resistance. The results showed that the fabricated antimicrobial nanofiber has the potential to be applied as a wound dressing for infected wound healing, although further studies are needed in vivo.
\end{abstract}

Supplementary information The online version contains supplementary material available at https://doi.org/10.1007/s10856021-06542-6.

Mehrdad Moosazadeh Moghaddam

mm.genetics@gmail.com

$\bowtie$ Mazaher Gholipourmalekabadi mazaher.gholipour@gmail.com

1 Applied Biotechnology Research Center, Baqiyatallah University of Medical Sciences, Tehran, Iran
2 Hematopoietic Stem Cell Research Center, Shahid Beheshti University of Medical Sciences, Tehran, Iran

3 Department of Tissue Engineering \& Regenerative Medicine, Faculty of Advanced Technologies in Medicine, Iran University of Medical Sciences, Tehran, Iran 


\section{Graphical Abstract}

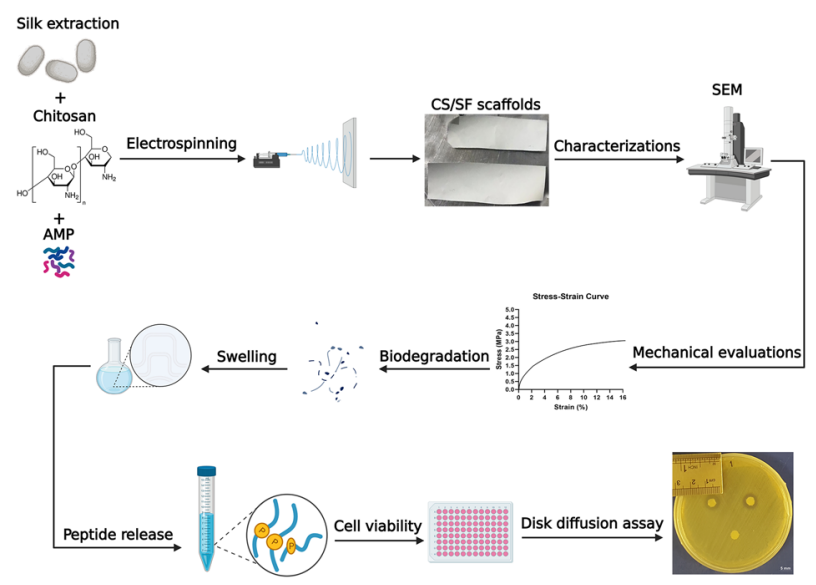

\section{Introduction}

Wound infections are among the most common infections, especially burns. Predominantly, antibiotic therapy along with using antiseptics like povidone-iodine in the wound bed is the most common treatment option for this type of infection. However, in some severe cases, hospitalization is required $[1,2]$. In these cases, the infection causes a prolonged inflammation activity and thus an extended healing period [3]. Unfortunately, in recent years, the remarkable emergence of bacteria that are resistant to antibiotics used to treat these types of infections has jeopardized the effective treatment of such wounds [4]. Therefore, it is necessary to use new strategies that accelerate the wound healing process by eliminating this type of infection. In the presented study, we have designed and developed an antimicrobial peptide (AMP)-loaded bilayer chitosan and silk fibroin (AMP-loaded CS/SF) electrospun nanofiber as a dressing for infected wounds and soft tissues applications.

Biomaterials-based wound dressings are now a choice to cover the wound site and facilitate the healing process. Ideally, a dressing should have mechanical properties enough to protect the wound bed, maintain homeostasis, be cytocompatible, and display antibacterial activity [5, 6]. Although the innate antibacterial properties can be a barrier to pathogen invasion, however, the addition of an antimicrobial agent to the dressing is now attracting more interest, especially with the increase of resistant bacteria [7]. In recent years, a significant number of studies have been performed on the fabrication of scaffolds with antimicrobial properties based on several strategies to produce wound dressings such as hydrogels [8] and electrospun membranes [7]. Among them, electrospun fibers have been used in biomedical applications in a wide range as they can act like a natural extracellular matrix for cell motility and propagation.
In addition, they provide a large surface-to-volume ratio due to their porous structure $[9,10]$. Natural biomaterials have been extensively applied for electrospinning purposes to be utilized as wound dressings due to biocompatibility reasons [11].

Chitosan (CS) is a natural polysaccharide derived from chitin that has some distinctive properties appropriate for biomedical purposes [12]. CS has shown biocompatibility, desired biodegradability, some degrees of antibacterial activities, and also is inexpensive which makes it a favorable option for tissue engineering and regenerative medicine applications [13, 14]. However, due to the mechanical weakness of using CS alone, its application is decreased [15]. Regarding this issue, it has been proposed to use CS in combination with some other mechanically strong materials [16]. Hence, its combination with silk fibroin (SF) can be one of the strategies. SF is the major protein of Bombyx mori silkworm cocoons that is famous for its toughness and elasticity. Additionally, due to its biocompatibility and easy handwork, it has been widely used in clinical studies in a wide range and some of its products have been approved by the FDA [17]. Previously, the successful electrospinning of the SF on the decellularized amniotic membrane surface has been reported for improving its mechanical properties [18]. Accordingly, we hypothesized to overcome the mechanical weakness of CS by the same strategy. Also, such electrospun mats have been used in combination with some antimicrobial agents as an antibacterial wound dressing [7].

Cationic AMPs, short peptides found in the immune system of many species, have recently received much attention as one of the most important alternatives to conventional antibiotics $[19,20]$. In general, they act directly against a wide range of pathogens such as bacteria, viruses, and fungi. Some of the AMPs are now commercially available [21, 22]. CM11 is a short cecropin-melittin-derived 
cationic AMP that is comprised of 11 amino acid residues (WKLFKKILKVL). This peptide has been shown in some studies to have antibacterial activity against many Grampositive and -negative antibiotic-resistant pathogens. $[23,24]$. Therefore, its potential for use in biomaterial-based wound dressings can be considered.

In the current study, an antibacterial CS/SF electrospun nanofiber containing different concentrations of CM11 peptide was fabricated and evaluated in vitro. For this purpose, the mechanical properties, biocompatibility, characterizations, and drug release profile of AMP-loaded CS-SF were examined. Eventually, the antibacterial activity of AMP-loaded CS-SF nanofiber was evaluated against standard and multi-drug resistant (MDR) strains of Escherichia coli, Staphylococcus aureus, and Pseudomonas aeruginosa isolated from burn patients in vitro. This optimized antibacterial wound dressing is introduced for future in vivo and clinical investigations of tissue engineering and regenerative medicine applications.

\section{Materials and methods}

\subsection{Bilayer scaffold fabrication}

\subsubsection{Silk fibroin extraction and characterization}

Fresh Bombyx mori silkworm cocoons were supplied from the Iranian Silkworm Research Center (Rasht, Iran). SF was extracted according to the method described by Gholipourmalekabadi et al. [25]. Briefly, cocoons were dissected and boiled in $0.02 \mathrm{M} \mathrm{Na}_{2} \mathrm{CO}_{3}$ solution for $1 \mathrm{~h}$. To remove the glue-like protein (Sericin), cocoons were completely rinsed with distilled water in a process called degumming. Then, for $4 \mathrm{~h}$ at $60^{\circ} \mathrm{C}$, the degummed $\mathrm{SF}$ was dissolved in 9.3 M Lithium Bromide ( $\mathrm{LiBr}$ ). Afterward, it was dialyzed against ultrapure water for $72 \mathrm{~h}$ (MWCO of $12 \mathrm{KDa}$ ). The final solution was lyophilized using a freeze-dryer apparatus (Nanbei, Zhengzhou, China) for $24 \mathrm{~h}$ and then restored at room temperature for further applications.

\subsubsection{Chitosan preparation}

To prepare CS solution for electrospinning, the polyvinyl alcohol (PVA, Sigma-Aldrich, St. Louis, MO, USA) was added to deionized water to form a $12 \% \mathrm{w} / \mathrm{v}$ solution and stirred for $4 \mathrm{~h}$ at $80^{\circ} \mathrm{C}(350 \mathrm{rpm})$. Next, the medium molecular weight CS (Sigma-Aldrich, St. Louis, MO, USA) was dissolved in 2\% acetic acid (Merck, Darmstadt, Germany) to prepare a $3 \% \mathrm{w} / \mathrm{v}$ solution and stirred on a magnetic stirrer for $15 \mathrm{~h}$. Afterward, this solution was added to PVA and gently stirred for an additional $2 \mathrm{~h}$. Then, it was stored at $4{ }^{\circ} \mathrm{C}$ for subsequent steps.

\subsubsection{Fabrication of antibacterial bilayer mat by direct electrospinning}

The bilayer mat was fabricated by direct electrospinning of AMP-loaded CS on ethanol-treated SF. For the electrospinning process, the lyophilized SF was dissolved in $98 \%$ formic acid (Sigma-Aldrich, USA) to form a $10 \%$ solution. The electrospinning was performed on an aluminum foilcovered collector for $6 \mathrm{~h}$ under the following conditions as described elsewhere [25]: a 2-ml syringe (gauge 23), $18 \mathrm{kV} /$ $\mathrm{cm}$ of voltage, $0.3 \mathrm{ml} / \mathrm{h}$ flow rate, and a $150 \mathrm{~mm}$ distance. Eventually, SF was immersed in $70 \%$ ethanol to induce $\beta$-sheet formation.

CM11 peptide (Biomatik, Canada) was added to prepared CS solution in 16, 32, and $64 \mu \mathrm{g} / \mathrm{ml}$ concentrations that are based on our previous study [26]. According to these studies, the MIC of peptide in the culture medium was $8 \mu \mathrm{g} / \mathrm{ml}$. To obtain a $50 / 50 \% \mathrm{v} / \mathrm{v}$ bilayer, the solution was electrospun on the SF fibers for another $9 \mathrm{~h}$ in a 2-ml syringe (gauge 23) under electrospinning conditions of a $20 \mathrm{kV}$ voltage, $0.2 \mathrm{ml} / \mathrm{h}$ of flow rate, and a distance of $200 \mathrm{~mm}$ as described by De Vrieze et al. [27] with some alterations. The bilayer was crosslinked by glutaraldehyde (GTA) vapor at the final stage.

\subsection{Scaffold characterizations}

\subsubsection{Silk fibroin characterization by FTIR}

To determine the functional groups of the extracted silk fibroin protein, the lyophilized SF was mixed with potassium bromide $(\mathrm{KBr})$. The formed pellets were analyzed by Fourier transform infrared spectroscopy (FTIR) using 55FTIR EQUINOX spectrophotometer (BrukerOptik $\mathrm{GmbH}$, Germany) in the range of $4000-400 \mathrm{~cm}^{-1}$ with a $4 \mathrm{~cm}^{-1}$ of resolution.

\subsubsection{Morphology of electrospun fibers}

The fabricated CS fibers and ethanol-treated SF scaffolds were gold-sputtered to be observed under the scanning electron microscope (SEM, AIS2100; Seron Technology, Uiwang-si, Gyeonggi-do, South Korea) at an acceleration voltage of $15 \mathrm{kV}$. The uniform structure of the scaffolds and the formation of fibers were expected to be observed without the presence of any beads.

\subsubsection{Mechanical evaluations}

All fabricated scaffolds were cut into rectangular pieces $(4 \mathrm{~cm} \times 1 \mathrm{~cm})$. Using a microtome (Thermo Fisher Scientific, Waltham, Massachusetts, USA) slices of $5 \mu \mathrm{m}$ in thickness were prepared for all samples to analyze and 
compare their mechanical characteristics under a universal tensile machine (Santam, Tehran, Iran). Using a $50 \mathrm{~N}$ load cell, the test was performed at a strain rate of $10 \mathrm{~mm} / \mathrm{min}$ $(n=5)$. The results were obtained from the stress-strain curve. The mean of each measurement was reported.

\subsubsection{In vitro biodegradation}

The biodegradation of the scaffolds was calculated by embedding $70 \pm 7 \mathrm{mg}$ of all samples $\left(M_{0}\right)$ into $10 \mathrm{ml}$ of simulated body fluid (SBF) supplemented with a $0.1 \mathrm{wt} \%$ enzyme (Merck, Darmstadt, Germany) and then, incubated at $37^{\circ} \mathrm{C}$. After incubation, three samples were removed from SBF at each predetermined time interval, washed with deionized water, and dried for $72 \mathrm{~h}$ at $25^{\circ} \mathrm{C}$. Afterward, the samples were weighed again $\left(M_{\mathrm{d}}\right)$, and according to the following equation the percentage of the lost weight was measured:

Weight $\operatorname{loss}(\%)=\frac{\mathrm{M} 0-\mathrm{Md}}{\mathrm{M} 0} \times 100$

\subsubsection{Swelling rate}

To determine the swelling rate of the bilayer scaffolds, dried scaffolds were weighed $\left(W_{\mathrm{d}}\right)$ and then, immersed in $5 \mathrm{ml}$ of deionized water for $24 \mathrm{~h}$ at $25^{\circ} \mathrm{C}$. Afterward, the scaffolds were removed from the water at each predetermined time interval and their wet weights were measured and denoted by $W_{\mathrm{s}}$. The swelling rate of the scaffolds was calculated according to the following formula:

Swelling rate $(\%)=\left(\left[\mathrm{W}_{\mathrm{s}}--\mathrm{W}_{\mathrm{d}}\right] / \mathrm{W}_{\mathrm{d}}\right)$

\subsubsection{In vitro peptide release}

To evaluate the release of CM11 peptide from the scaffolds, they were submerged in PBS at $37^{\circ} \mathrm{C}$ for eight consecutive days. After each time interval, the optical density of the samples was measured at $280 \mathrm{~nm}$ using NanoDrop One microvolume UV-Vis Spectrophotometers (Thermo Fisher Scientific, Waltham, Massachusetts, United States). The results were the mean of three different examinations.

\subsection{Biocompatibility assay}

\subsubsection{Cell viability}

For cell viability assessment, the MTT assay was performed. In brief, the scaffolds were seeded by Hu02 human foreskin fibroblast cells obtained from the Iranian Biological Resource Center (Tehran, Iran) for 1,3 , and 7 days at $37^{\circ} \mathrm{C}$ under standard conditions (95\% humidity and $5 \% \mathrm{CO}_{2}$ ).
After each time interval, the samples were treated by 3-(4,5Dimethyl-2-thiazolyl)-2,5-diphenyl-2H-tetrazolium bromide (MTT) solution for $4 \mathrm{~h}$ at $37^{\circ} \mathrm{C}$ in dark. Afterward, the formed tetrazolium crystals were dissolved in Dimethyl sulfoxide (DMSO) for 15 minutes in dark. This method was repeated thrice and all the results were compared to control (cells cultured in cell culture plate) using a plate-reader (DANA, DA3200) at $570 \mathrm{~nm}$. The viability of the cells grown on the cell culture plate (control sample) was considered $100 \%$. The scaffolds showing some degrees of toxicity were excluded from further assessments.

\subsubsection{Scaffold-cell interaction}

The cells were seeded on the scaffolds and incubated for 3 days at $37{ }^{\circ} \mathrm{C}$ under standard conditions (95\% humidity and $5 \% \mathrm{CO}_{2}$ ). For taking images under SEM, the cellseeded scaffolds were fixed with $2.5 \%$ glutaraldehyde (Merck, Darmstadt, Germany) for $2 \mathrm{~h}$. The samples were then submerged in phosphate-buffered saline (PBS) at $25^{\circ} \mathrm{C}$ for $30 \mathrm{~min}$. afterward, they were dehydrated by a graded series $(30,50,70$, and $100 \%)$ of ethanol, and followed by drying under vacuum for $12 \mathrm{~h}$. After gold sputtering, the scaffolds were observed under SEM.

\subsection{Antibacterial activity}

Based on MTT results, the antibacterial activity of the CS/ SF, Peptide-loaded CS/SF $(16 \mu \mathrm{g} / \mathrm{ml})$ and Peptide-loaded CS/SF $(32 \mu \mathrm{g} / \mathrm{ml})$ scaffolds was evaluated against standard strains of Staphylococcus aureus (ATCC 25923), Escherichia coli (ATCC 25922), Pseudomonas aeruginosa (ATCC 28753), and their MDR strains (MDR 50, all) isolated from burn patients by disk diffusion assay according to clinical and laboratory standards institute guidelines [28]. Briefly, $100 \mu \mathrm{l}$ of $0.5 \mathrm{McF}$ arland $\left(1.5 \times 10^{8} \mathrm{CFU} / \mathrm{ml}\right)$ bacterial suspensions were cultured on Mueller-Hinton Agar (MHA) plates. Then, the prepared disks of the samples $(0.5 \mathrm{~cm}$ in diameter) were placed on the center of plates, and were incubated at $37^{\circ} \mathrm{C}$ for $24 \mathrm{~h}$. The inhibition zone of bacterial growth was reported using a ruler and compared among samples. All human sample collections were approved by the Baqiyatallah University of Medical Sciences ethical committee under approval ID of IR.BMSU. REC.1398.361.

\subsection{Statistical analysis}

All the experiments were conducted in triplicates or with at least three different samples and the mean of each was recorded. The collected data were analyzed using GraphPad Prism v8.0.2.263 software. Where appropriate, independent samples $t$ test or One-way ANOVA were applied. The data 
Fig. 1 FTIR spectra of silk fibroin. FTIR spectra of silk fibroin. The bands at $1648 \mathrm{~cm}^{-1}$, $1513 \mathrm{~cm}^{-1}$, and $1241 \mathrm{~cm}^{-1}$ represent amide $\mathrm{I}(\mathrm{C}=\mathrm{O}$ stretching), amide II (secondary $\mathrm{N}-\mathrm{H}$ bending) and amid III (C-N and $\mathrm{N}-\mathrm{H}$ functionalities) groups, respectively

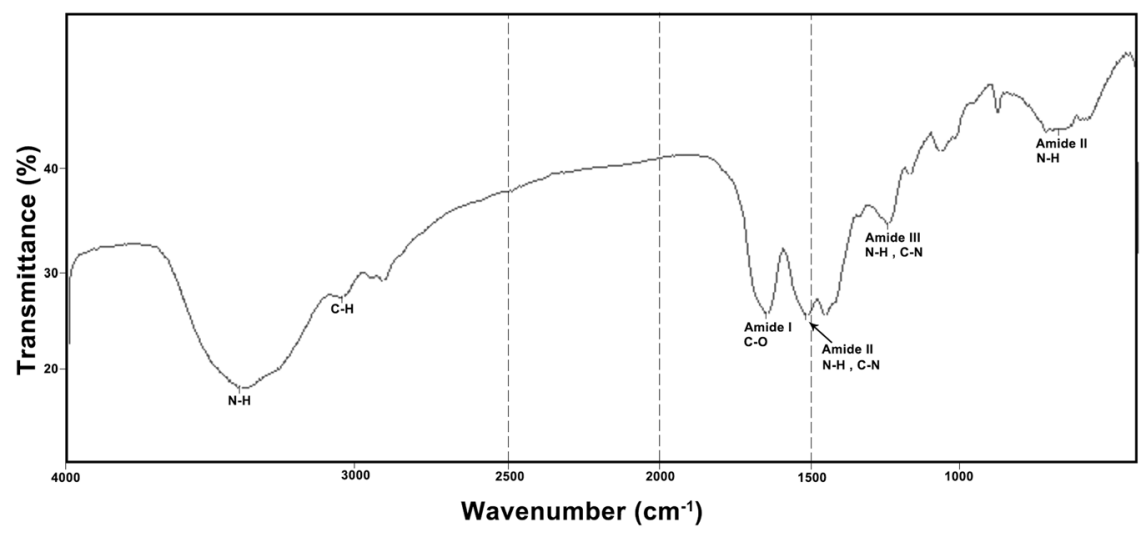

Fig. 2 The ultrastructure of the electrospun CS and electrospun $\mathrm{SF}$ after treating with ethanol observed under SEM

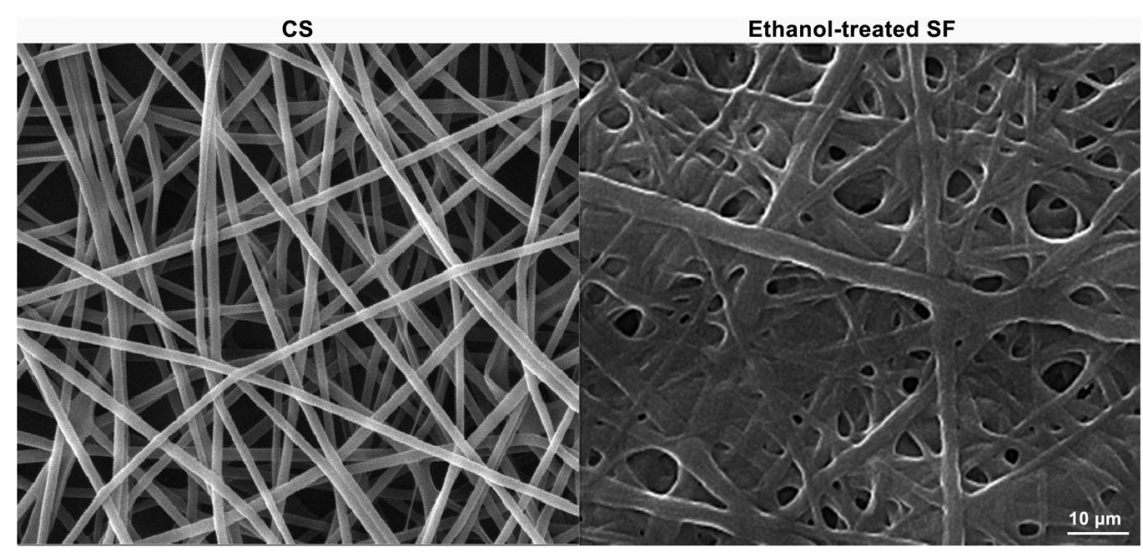

were expressed as mean $\pm \mathrm{SD}$. In addition, $P<0.05$ was considered as the level of significance.

\section{Results}

\subsection{Scaffold characterizations}

\subsubsection{Silk fibroin characterization by FTIR}

FTIR was performed to confirm the molecular composition of the extracted SF protein before ethanol treatment. As shown in Fig. 1, proteins display characteristic vibration peaks at $1650-1630 \mathrm{~cm}^{-1}, 1540-1520 \mathrm{~cm}^{-1}$, and $1270-1230 \mathrm{~cm}^{-1}$ for Amide I, amide II, and amide III, respectively. These peaks are distinguishable vibration peaks for all protein samples.

\subsubsection{Morphology electrospun fibers}

The morphology of the electrospun CS and SF (after ethanol treatment) scaffolds under SEM is presented in Fig. 2. The uniform structure of the fibers without bead formation is distinctly evident in both scaffolds. However, ethanol induces the $\beta$-sheet formation to the SF fibers and thus improves the biomechanical properties of the final product.
Table 1 The biomechanical properties of the electrospun SF, CS, and SF/CTS scaffolds

\begin{tabular}{llll}
\hline Material & SF & CS & CS/SF \\
$\begin{array}{l}\text { Ultimate tensile } \\
\text { strength [MPa] }\end{array}$ & $4.33 \pm 0.04$ & $3.89 \pm 0.29$ & $4.15 \pm 0.19$ \\
Elongation at break $(\%)$ & $10.9 \pm 0.05$ & $6.9 \pm 0.45$ & $10.4 \pm 0.73$ \\
\hline
\end{tabular}

\subsubsection{Mechanical evaluations}

Mechanical properties are essential determinants of a biomaterial appropriate to be used in tissue engineering. The results obtained from the stress-strain curve are summarized in Table 1. As expected, electrospinning of SF has improved the mechanical properties of CS. It clearly can be apprehended from the table that there is a considerable difference between the electrospun CS/SF bilayer with electrospun CS. The bilayer displays mechanical characteristics similar to electrospun SF. As SF is one of the toughest known biomaterials, these results are considerable.

\subsubsection{In vitro biodegradation}

Figure 3, shows the biodegradation rate of the samples in a time period of 35 days in enzyme-supplemented SFB. CS 


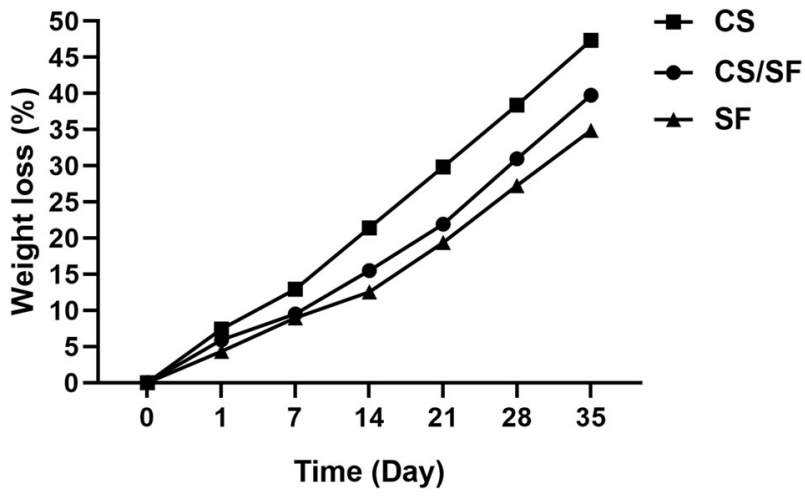

Fig. 3 The biodegradation rate of the scaffolds after 35 days. CS significantly degrades faster from day 1 to 35 compared to other samples in all time intervals $(P<0.05)$. There are no significant differences between SF and CS/SF scaffolds during 21 days $(P>0.05)$. $\mathrm{CS} / \mathrm{SF}$ sample degrades significantly faster than SF alone from day 21 to 35 in all-time intervals $(P<0.05)$

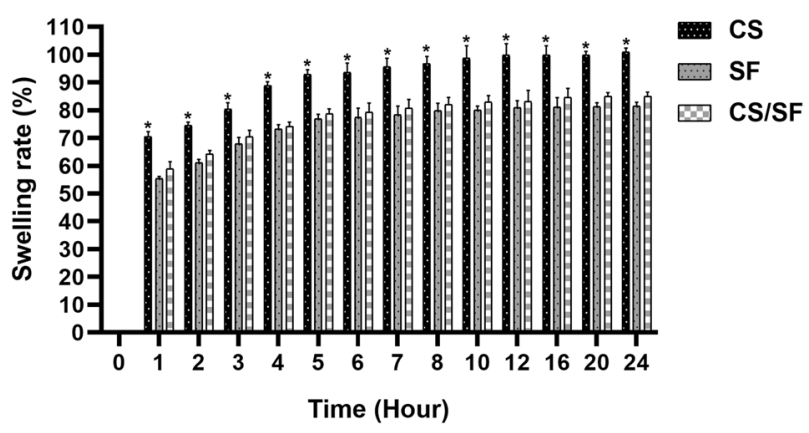

Fig. 4 The swelling rate of scaffolds. The figure shows a similar swelling pattern among all samples within $24 \mathrm{~h}$. However, CS shows a significant water uptake in all time intervals compared with SF and $\mathrm{CS} / \mathrm{SF}$ samples $(P<0.0001)$. There are no considerable differences between $\mathrm{SF}$ and $\mathrm{CS} / \mathrm{SF}$ samples in all predetermined time intervals. * represents a significant difference with SF and CS/SF $(P<0.0001)$

degrades faster and losses almost half of its initial weight within 35 days. SF and CS/SF experimental samples follow approximately a similar manner in 3 weeks. However, from day 21 to 35, CS/SF scaffold shows more biodegradation compared to SF. The differences among samples containing SF with chitosan are significant $(P<0.05)$. After 35 days, the bilayer lost almost $40 \%$ of its dry weight. The results emphasize the effect of SF on the desirable degradation of CS in the bilayer.

\subsubsection{Swelling rate}

The water absorption examination also revealed a significant difference between SF and CS/SF scaffolds with CS $(P<0.05)$. According to Fig. 4, a dramatic water uptake after $4 \mathrm{~h}$ and a slight increase between 5 and $10 \mathrm{~h}$ is observable among all three samples. However, the CS sample absorbs more water than FS and CS/SF. After the

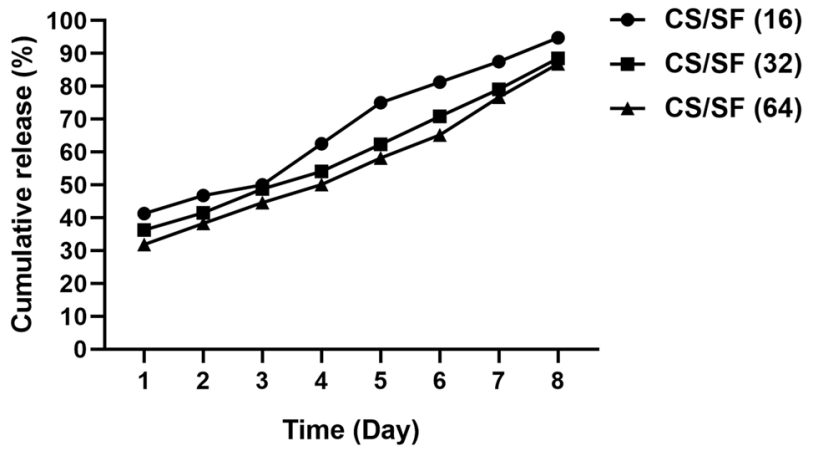

Fig. 5 The release pattern of CM11 peptide from the scaffolds. A burst release of the peptide at day 1 , and an increase in a linear manner until day 8 is evident in the figure in all samples. Approximately $90 \%$ of the peptide is released through 8 consecutive days from all three experimental samples

first $10 \mathrm{~h}$, a constant level of water absorption is represented up to $24 \mathrm{~h}$ in all experimental samples. Although SF and $\mathrm{CS} / \mathrm{SF}$ samples display high water uptake, the swelling rate of CS is around twofold after $24 \mathrm{~h}$.

\subsubsection{In vitro peptide release}

Peptide-loaded SF/CTS samples containing 16, 32, and $64 \mu \mathrm{g} / \mathrm{ml}$ peptide, respectively, were considered to study their release behavior in vitro. According to the results represented in Fig. 5, a burst release of CM11 peptide from scaffolds is recorded after day 1 (more than $30 \%$ in all samples). An increase in the release of peptides from the bilayer in a linear manner is observable up to 8 days, as all scaffolds released almost $90 \%$ of their peptide until this day. All three samples display almost a similar pattern with different rates.

\subsection{Biocompatibility assay}

Cell viability and attachment assays are performed to show the compatibility of the products to native residential cells.

\subsubsection{Cell viability}

The fabricated bilayer scaffold and bilayer scaffolds loaded with different concentrations of CM11 peptide were investigated by MTT assay in 1, 3, and 7 days and compared with control (seeded cells without scaffolds) to check if they induce cytotoxicity. As demonstrated in Fig. 6A, there were no significant differences between the underexamination scaffolds with control on day 1 post-seeding. However, on days 3 and 7, a significant decrease in $\mathrm{Hu} 02$ fibroblast cells' growth was observed in the peptide-loaded SF/CTS scaffold ( $64 \mu \mathrm{g} / \mathrm{ml}$ peptide) compared with the control. Meantime, no considerable differences with control were recorded in 3 other samples in any predetermined time 


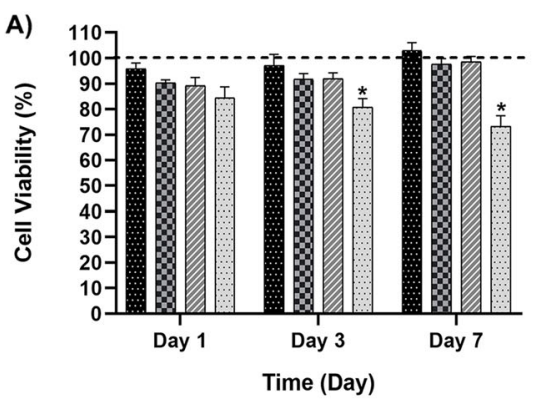

Fig. 6 A Cell viability results of the 4 investigated bilayer scaffolds with different concentrations of the peptide, show a significant difference in fibroblasts' growth of peptide-loaded CS/SF $(64 \mu \mathrm{g} / \mathrm{ml}$

interval. As the results, the peptide-loaded SF/CTS scaffold containing $64 \mu \mathrm{g} / \mathrm{ml}$ peptide was excluded from the study, and the other groups were considered for further evaluation.

\subsubsection{Cell attachment}

The adhesion of cells to the scaffolds is a direct representative of the cell-scaffold adaptation. Here in Fig. 6B, the morphology of a Hu02 fibroblast cell well attached to the surface of the fibers is clearly observable after 3 days of culturing on the bilayer.

\subsection{Antibacterial activity}

The results taken from the disk diffusion assay are presented in Fig. 7. CS/SF and peptide-loaded CS/SF (16 and $32 \mu \mathrm{g} /$ $\mathrm{ml}$ peptide, respectively) disks were placed in MHA plates cultured with standard and resistant strains of S. aureus, E. coli, and $P$. aeruginosa, and incubated for $24 \mathrm{~h}$. According to the results (Fig. 7A), the CS/SF scaffold shows no antibacterial activity at all, while in peptide-loaded CS/SF $(16 \mu \mathrm{g} / \mathrm{ml})$ scaffold, a bacterial growth inhibition zone is evident against standard strains. This scaffold has no antibacterial effects on resistant bacteria isolated from burn patients. Meanwhile, a zone of growth inhibition against all standard and resistant strains are revealed around disks of peptide-loaded CS/SF $(32 \mu \mathrm{g} / \mathrm{ml})$ scaffold. Figure 7B demonstrates the size of the halo around an experimental disk, while the analysis of the recorded diameters is presented in Fig. 7C to quantify the results taken from the disk diffusion assay.

\section{Discussion}

This study was presented to inquire about the ability of an AMP-loaded CS/SF electrospun bilayer mat as a possible scaffold for wound infection applications. In recent years, antimicrobial peptides have been considered as a promising peptide) scaffold and the control in days 3 and 7 post-seeding. B adhesion of a fibroblast cell to the surface of the bilayer fibers. White and red arrows represent the fibers and cell filopodia, respectively

option for the post-antibiotic era in many studies [29-32]. These peptides are important members of the host defense system in eukaryotes that have a broad function in wound healing, immune regulation, and inflammation, and act as endogenous antibiotics [33]. Due to their antimicrobial and biological potentials, these peptides have also been considered for wound dressing purposes. [8, 34, 35]. Accordingly, many studies have been done to use these peptides against infections caused by antibiotic-resistant bacterial strains. However, these peptides may have cytotoxic effects, so their controlled-release can be effective in reducing cytotoxicity. CM11 is a synthetic hybrid of cecropinmelittin that has shown stronger antibacterial activities than both of its compartments with less hemolytic and cytotoxic effects [36]. Studies have shown that the antimicrobial activity of this peptide may be associated with its ability to cell membrane infiltration and disruption via the formation of pores in cell membranes [37]. Here, we designed and fabricated an electrospun bilayer of SF and CS scaffold for controlled-delivery of CM11 peptide and examined its potential as a dressing for infected wounds with the determination of its antimicrobial activity against MDR strains of Gram-negative and -positive bacteria especially $P$. aeruginosa as the most common Gram-negative strain in burn patients.

Electrospinning of polyelectrolyte materials that possess electric charges along a chain like CS is difficult as they display greater shear thinning than neutrals [38]. As the result, CS has been electrospun in blended solutions with other electrospinnable materials such as PVA, that can interact with CS through hydrogen bonding [39]. Despite a uniform structure, the fibers formed from the blended solution of CS/PVA are mechanically weak. Thus, the addition of another layer with strong mechanical characteristics like SF makes sense. The electrospun SF was immersed in ethanol to induce the $\beta$-sheet formation and become insoluble in aqueous media [17]. Then, the mixed solution of CS/PVA and CM11 peptide was electrospun on ethanol-treated SF. The final product was crosslinked using 


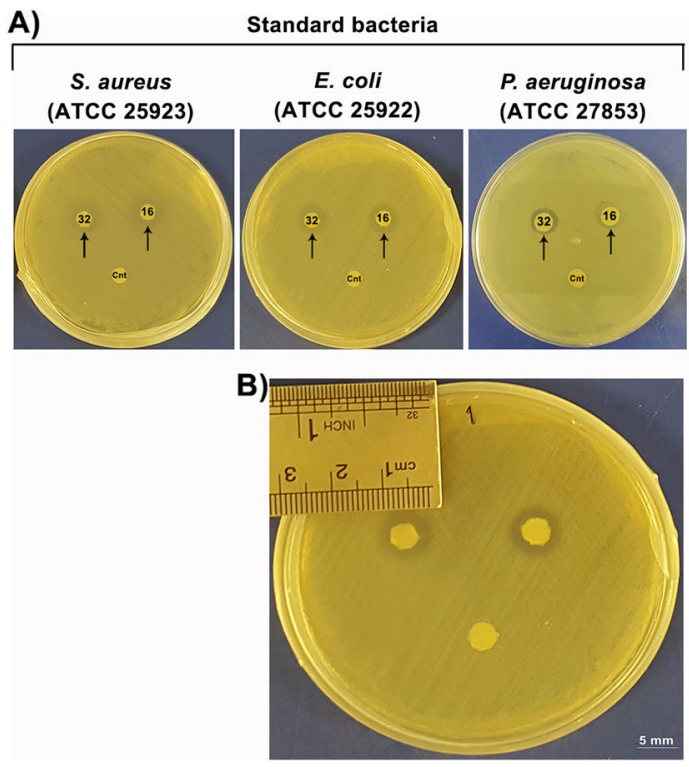

Fig. 7 Assessment of antibacterial activity peptide-loaded CS/FS by disk diffusion assay. A The antibacterial activity peptide-loaded CS/SF (16 \& $32 \mu \mathrm{g} / \mathrm{ml}$ peptide, respectively) bilayers are compared with control (Cnt). A halo around peptide-loaded bilayers is visible after $24 \mathrm{~h}$ in standard strains of $S$. aureus, E. coli, and P. aeruginosa MHA plates compared to control disks. In resistant strains, an inhibition zone is observable only around CS/SF containing $32 \mu \mathrm{g} / \mathrm{ml} \mathrm{CM} 11$ peptide. B The diameter of the growth inhibition zone recorded by a ruler.

GTA vapor to become insoluble in water and form a solid bond between layers [40].

FTIR data reported from previous studies revealed that SF shows characteristic vibration peaks related to the amides group at around $1650 \mathrm{~cm}^{-1}$ (amide I), $1525-1540 \mathrm{~cm}^{-1}$ (amide II) and $1266 \mathrm{~cm}^{-1}$ (amide III) for $\alpha$-helix motif, around $1620 \mathrm{~cm}^{-1}$ (amide I), $1514 \mathrm{~cm}^{-1}$ (amide II) and $1230 \mathrm{~cm}^{-1}$ (amide III), to $\beta$-sheet structure, $1655 \mathrm{~cm}^{-1}$ (amide I), $1540 \mathrm{~cm}^{-1}$ (amide II) and $1235 \mathrm{~cm}^{-1}$ (amide III) representing random coil structure [41, 42]. Similar to these reports, findings in the current study demonstrating the silk I structure of a pure SF.

The morphology of electrospun CS and SF fibers (after immersing in ethanol) reveals a highly porous and uniformed structure with interconnected networks under SEM. This structure is appropriate for a scaffold implanted in the wound bed for cell migration and proliferation and nutrients entry. The structure along with the mechanical properties of a scaffold is directly related to its potential clinical applications [43]. There are various reports in the literature regarding the addition of biodegradable biomaterials to improve the mechanical characteristics of CS scaffolds [4446]. The addition of SF fibers has significantly enhanced these properties. According to $\mathrm{Xu}$ et al. [47], these characteristics are due to the content, distribution, and adhesion of the fibers. However, these improvements are most likely

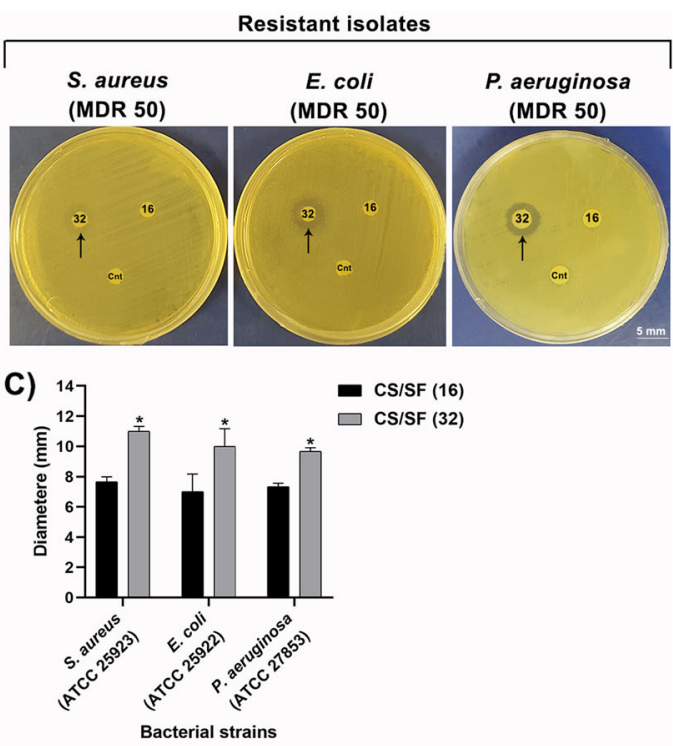

C Diameters around peptide-loaded CS/SF $(16 \mu \mathrm{g} / \mathrm{ml})$ disks are compared to peptide-loaded CS/SF $(32 \mu \mathrm{g} / \mathrm{ml})$. There are significant differences in the scaffolds containing higher concentrations of CM11 peptide $(32 \mu \mathrm{g} / \mathrm{ml})$ with peptide-loaded CS/SF containing $16 \mu \mathrm{g} / \mathrm{ml}$ peptide in both standard strains $(P<0.05)$. Results from resistant strains and all controls are excluded as no diameters have formed and there is nothing to compare

related to the hydrogen bonding of SF's amide groups with $\mathrm{N}-\mathrm{H}$ of CS [48].

Our biodegradation results demonstrated that the addition of SF fibers to electrospun CS effectively decreased the rate of biodegradation. In general, biodegradation of a scaffold is an essential determinant of its competence for tissue engineering approaches especially when acts as an agent carrier. A fast degradation causes a fast release of drugs and also, limits the chance of cell migration and proliferation critical for tissue regeneration. This parameter is highly related to the swelling ratio of the CS and SF alone and in combination. The swelling ratio itself displays the ability of a scaffold to absorb surrounding exudates and provide an aqueous medium required for cell growth [47, 48]. Despite the decrease in swelling rate with the addition of SF fibers compared to CS, the CS/SF scaffold still possesses around $85 \%$ rate which is appropriate for its functions in skin wound healing applications. This decrease in water uptake is due to the fact that the hydrophobic structure of SF reduces the affinity of SF-containing scaffolds with water molecules [47]. The prolonged biodegradation rate of the CS/SF scaffold facilitates the new tissue formation and controlled release of drugs [49]. The release assessment of the CM11 peptide with different concentrations from the bilayer scaffold revealed around $90 \%$ sustainable release in 8 consecutive days in all samples. A $30-40 \%$ initial release was 
observed in the experimental samples. This burst release on the first day may be the result of weak physical interactions of the AMP with the bilayer. Sustained release of the peptides and drugs will decrease their potential side effects and increases their effectiveness [50].

The interactions of $\mathrm{Hu} 02$ human foreskin fibroblasts with peptide-loaded CS/SF scaffold exhibited a well-attached and growth of cells on its surface confirmed by SEM. MTT assay was also performed to analyze the viability of these cells in contact with different concentrations of the CM11 loaded on bilayers. The results demonstrated cytotoxicity effects on the viability of cells co-cultured with $\mathrm{CS} / \mathrm{SF}$ bilayer containing $64 \mu \mathrm{g} / \mathrm{ml}$ peptide on days 3 and 7 . Therefore, this scaffold was excluded from further analysis. However, no cytotoxicity was detected in scaffolds with fewer concentrations of the peptide in 7 days. These findings are in concordance with our previous study that emphasized the dose-dependent viability of Hela, $\mathrm{CHO}$, and LNCAP cells in contact with CM11 peptide $[33,50]$.

Disk diffusion assay was performed to evaluate the peptide-loaded bilayers' antibacterial effects on a broad spectrum of bacterial strains. Our previous studies demonstrated the antibacterial activity of CM11 peptide against MDR strains of a wide range of pathogenic bacteria including Staphylococcus aureus, Pseudomonas aeruginosa, Vibrio cholerae, Acinetobacter baumannii, Escherichia coli, Klebsiella pneumonia, Brucella melitensis, and Salmonella typhimurium [19, 24, 33, 37]. Accordingly, the results of this study exhibited antibacterial activity of CM11 peptide-loaded CS/SF bilayer against standard strains of $S$. aureus, E. coli, P. aeruginosa along with their MDR strains isolated from burn patients in a dose-dependent manner. Peptide-loaded scaffolds showed a growth inhibition zone around themselves in the cultivation of standard strains, while no zone around the CS/SF disc without peptide was observed. However, the diameter size of the zones was significantly different between peptide-loaded CS/SF disks with 16 and $32 \mu \mathrm{g} / \mathrm{ml}$ concentrations, so that, the diameter of the zone was higher around the disk contained $32 \mu \mathrm{g} / \mathrm{ml}$ of the peptide. But, in MDR strains, a growth inhibition zone was observed only around peptide-loaded CS/SF disk with $32 \mu \mathrm{g} / \mathrm{ml}$ peptide. It worth to be mentioned that in disk diffusion assay the plates should not be incubated for more than $24 \mathrm{~h}$, as this may generate invalid outcomes [28, 51]. According to this and results obtained from in vitro release profile, it demands further investigations for possible bacterial resistance to CM11 in vivo.

In general, electrospun fiber dressings are one potential technology that has been significantly investigated in recent years for wound dressing applications. They have significant advantages that make them ideal for use as wound healing dressings because they provide potential advantages in terms of increased surface area that creates a physical barrier to bacterial invasion and biofilm formation but they still retain the oxygen and gas transfer ability necessary for wound healing [52]. Similar to the current study, in a study by Song et al., an antimicrobial peptide-immobilized silk fibroin nanofiber membrane was evaluated for wound dressing application. For this purpose, an antimicrobial peptide (KR12: KRIVKRIKKWLR) originating from human cathelicidin peptide (LL37) was immobilized onto electrospun SF nanofiber membranes. Their findings confirmed antimicrobial activity against standard strains of Staphylococcus aureus, Staphylococcus epidermidis, Escherichia coli, and Pseudomonas aeruginosa. Similar to the CM11 peptide, the MIC of KR12 peptide was $8 \mu \mathrm{g} / \mathrm{ml}$ but they used $50,100,200$, and $500 \mu \mathrm{g} / \mathrm{ml}$ concentrations of this peptide for fabrication of peptide-conjugated SF nanofiber membrane. According to the results, at a concentration of $200 \mu \mathrm{g} / \mathrm{ml}$, bacterial growth was significantly inhibited. This membrane also facilitated the proliferation of keratinocytes and fibroblasts and promoted the enhanced cell-cell attachment [53]. However, the antimicrobial activity of these membranes against antibiotic-resistant strains has not been evaluated. Also, Chouhan et al., evaluated LL37-loaded PVA-silk blended nanofibrous mats as dressing application for diabetic wound healing. For this purpose, the LL37 antimicrobial peptide was loaded at $50 \mu \mathrm{g} / \mathrm{ml}$ concentration in nanofiber and used against standard strains of Staphylococcus epidermidis, and Pseudomonas aeruginosa. The antibacterial property of LL-37 functionalized mats was observed under both in vitro and in vivo conditions. According to their results, functionalized mats efficiently killed skin infecting $P$. aeruginosa and $S$. epidermidis bacteria. Compared to the present study, they used a peptide with a higher number of amino acids (37 aa) as well as at a higher concentration which can be increased costs [54]. On the other hand, Cai et al., fabricated a CS/SF scaffold and evaluated its antimicrobial activity alone based on the antimicrobial property of the CS against standard strains of $E$. coli and $S$. aureus. The results showed that the composite CS/SF membranes had only an antibacterial effect on E. coli, which its antibacterial effect increased with the increase of chitosan content. Their results demonstrated that the chitosan content is the main element of the composite which has the antibacterial effect, and its activity is varied on types of bacteria. In comparison with this study, we showed that the addition of peptide can limit the growth of MDR Gram-positive and -negative bacteria [40]. In another study conducted by $\mathrm{Xu}$ et al., [47], they examined the wound healing effects of chitosan/silk microfiber membrane on a full-thickness skin wound of rats. According to their findings, the addition of SF microfibers can increase the efficiency of wound healing compared to CS 
membrane alone. Therefore, the potential of CS/SF scaffold on infected skin wounds regeneration and repair can be perceived from the results of previous and present studies.

\section{Conclusion}

The current study represents the antibacterial activity of an AMP-loaded CS/SF electrospun bilayer scaffold proposed for infected wound healing applications, especially for infections by MDR bacterial strains. Obtained results suggest the potential of peptide-loaded CS/FS bilayer containing $32 \mu \mathrm{g} / \mathrm{ml}$ of the CM11 peptide as a candidate dressing for infected wounds with MDR bacteria without cytotoxicity. We strongly believe that fabricated scaffold can be considered for in vivo studies of not only infected skin wounds but for all types of all tissues. Eventually, it looks promising as a candidate for clinical investigations.

Acknowledgements The authors would like to thank the guidance and advice of the "Clinical Research Development Unit of Baqiyatallah Hospital". They would also like to express their gratitude to all the coworkers in the Baqiyatallah University of Medical Sciences for their technical assistance.

\section{Compliance with ethical standards}

Competing interests The authors declare no competing interests.

Publisher's note Springer Nature remains neutral with regard to jurisdictional claims in published maps and institutional affiliations.

Open Access This article is licensed under a Creative Commons Attribution 4.0 International License, which permits use, sharing, adaptation, distribution and reproduction in any medium or format, as long as you give appropriate credit to the original author(s) and the source, provide a link to the Creative Commons license, and indicate if changes were made. The images or other third party material in this article are included in the article's Creative Commons license, unless indicated otherwise in a credit line to the material. If material is not included in the article's Creative Commons license and your intended use is not permitted by statutory regulation or exceeds the permitted use, you will need to obtain permission directly from the copyright holder. To view a copy of this license, visit http://creativecommons. org/licenses/by/4.0/.

\section{References}

1. Petkovsek Z, Elersic K, Gubina M, Zgur-Bertok D, Starcic, Erjavec M. Virulence potential of Escherichia coli isolates from skin and soft tissue infections. J Clin Microbiol. 2009;47:1811-7.

2. Bigliardi PL, Alsagoff SAL, El-Kafrawi HY, Pyon J-K, Wa CTC, Villa MA. Povidone iodine in wound healing: A review of current concepts and practices. Int J Surg. 2017;44:260-8.

3. Zhao Y, Liu JG, Chen WM, Yu AX. Efficacy of thermosensitive chitosan/ $\beta$-glycerophosphate hydrogel loaded with $\beta$-cyclodextrin-curcumin for the treatment of cutaneous wound infection in rats. Exp Ther Med. 2018;15:1304-13.
4. Xu Z-Q, Flavin MT, Flavin J. Combating multidrug-resistant Gram-negative bacterial infections. Exp Opin Investig Drugs. 2014;23:163-82.

5. Zhao R, Li X, Sun B, Zhang Y, Zhang D, Tang Z, et al. Electrospun chitosan/sericin composite nanofibers with antibacterial property as potential wound dressings. Int $\mathrm{J}$ Biol Macromol. 2014;68:92-7.

6. Çalamak S, Erdoğdu C, Özalp M, Ulubayram K. Silk fibroin based antibacterial bionanotextiles as wound dressing materials. Mater Sci Eng C. 2014;43:11-20.

7. Augustine R, Kalarikkal N, Thomas S. Electrospun PCL membranes incorporated with biosynthesized silver nanoparticles as antibacterial wound dressings. Appl Nanosci. 2016;6:337-44.

8. Rezaei N, Hamidabadi HG, Khosravimelal S, Zahiri M, Ahovan ZA, Bojnordi MN, et al. Antimicrobial peptides-loaded smart chitosan hydrogel: Release behavior and antibacterial potential against antibiotic resistant clinical isolates. Int J Biol Macromol. 2020;164:855-62.

9. Sill TJ, von Recum HA. Electrospinning: Applications in drug delivery and tissue engineering. Biomaterials. 2008;29:1989-2006.

10. Zahedi P, Rezaeian I, Ranaei-Siadat S-O, Jafari S-H, Supaphol P. A review on wound dressings with an emphasis on electrospun nanofibrous polymeric bandages. Polym Adv Technol. 2010;21:77-95.

11. Ahovan ZA, Khosravimelal S, Eftekhari BS, Mehrabi S, Hashemi A, Eftekhari S, et al. Thermo-responsive chitosan hydrogel for healing of fullthickness wounds infected with XDR bacteria isolated from burn patients: In vitro and in vivo animal model. Int $\mathrm{J}$ Biol Macromol. 2020;164:4475-86.

12. Dang Q, Liu K, Zhang Z, Liu C, Liu X, Xin Y, et al. Fabrication and evaluation of thermosensitive chitosan/collagen/ $\alpha$, $\beta$-glycerophosphate hydrogels for tissue regeneration. Carbohydr Polym. 2017;167:145-57.

13. Dai T, Tanaka M, Huang Y-Y, Hamblin MR. Chitosan preparations for wounds and burns: antimicrobial and wound-healing effects. Expert Rev Anti-Infective Ther. 2011;9:857-79.

14. Farhadihosseinabadi B, Zarebkohan A, Eftekhary M, Heiat M, Moghaddam MM, Gholipourmalekabadi M. Crosstalk between chitosan and cell signaling pathways. Cell Mol Life Sci. 2019;76:1-22.

15. Chanda A, Adhikari J, Ghosh A, Chowdhury SR, Thomas S, Datta $\mathrm{P}$, et al. Electrospun chitosan/polycaprolactone-hyaluronic acid bilayered scaffold for potential wound healing applications. Int J Biol Macromol. 2018;116:774-85.

16. Zhang H, Luo X, Lin X, Lu X, Zhou Y, Tang Y. Polycaprolactone/chitosan blends: Simulation and experimental design. Mater Des. 2016;90:396-402.

17. Gholipourmalekabadi M, Khosravimelal S, Nokhbedehghan Z, Sameni M, Jajarmi V, Urbanska AM, et al. Modulation of hypertrophic scar formation using amniotic membrane/electrospun silk fibroin bilayer membrane in a rabbit ear model. ACS Biomater Sci Eng. 2019.

18. Gholipourmalekabadi M, Samadikuchaksaraei A, Seifalian AM, Urbanska AM, Ghanbarian H, Hardy JG, et al. Silk fibroin/ amniotic membrane 3D bilayered artificial skin. Biomed Mater. 2018;13:035003.

19. Moghaddam MM, Abolhassani F, Babavalian H, Mirnejad R, Barjini KA, Amani J. Comparison of in vitro antibacterial activities of two cationic peptides CM15 and CM11 against five pathogenic bacteria: Pseudomonas aeruginosa, Staphylococcus aureus, Vibrio cholerae, Acinetobacter baumannii, and Escherichia coli. Probiot Antimicrob Proteins. 2012;4:133-9.

20. Moghaddam MM, Aghamollaei H, Kooshki H, Barjini KA, Mirnejad R, Choopani A. The development of antimicrobial peptides as an approach to prevention of antibiotic resistance. Rev Med Microbiol. 2015;26:98-110. 
21. Fox JL. Antimicrobial peptides stage a comeback. Nature Publishing Group; 2013.

22. Mahlapuu M, Håkansson J, Ringstad L, Björn C. Antimicrobial Peptides: An Emerging Category of Therapeutic Agents. Frontiers in Cellular and Infection. Microbiology. 2016;6:(194).

23. Khalili S, Mohebali M, Ebrahimzadeh E, Shayan E, MohammadiYeganeh S, Moghaddam MM, et al., editors. Antimicrobial activity of an antimicrobial peptide against amastigote forms of Leishmania major. Veterinary Research Forum; 2018: Faculty of Veterinary Medicine, Urmia University, Urmia, Iran.

24. Moghaddam MM, Eftekhary M, Erfanimanesh S, Hashemi A, Omrani VF, Farhadihosseinabadi B, et al. Comparison of the antibacterial effects of a short cationic peptide and $1 \%$ silver bioactive glass against extensively drug-resistant bacteria, Pseudomonas aeruginosa and Acinetobacter baumannii, isolated from burn patients. Amino Acids. 2018;50:1617-28.

25. Gholipourmalekabadi M, Mozafari M, Bandehpour M, Salehi M, Sameni M, Caicedo HH, et al. Optimization of nanofibrous silk fibroin scaffold as a delivery system for bone marrow adherent cells: in vitro and in vivo studies. Biotechnol Appl Biochem. 2015;62:785-94.

26. Amani J, A Barjini K, Moghaddam M, Asadi A. In vitro synergistic effect of the CM11 antimicrobial peptide in combination with common antibiotics against clinical isolates of six species of multidrug-resistant pathogenic bacteria. Protein Peptide Lett. 2015;22:940-51.

27. De Vrieze S, Westbroek P, Van Camp T, Van Langenhove L. Electrospinning of chitosan nanofibrous structures: feasibility study. J Mater Sci. 2007;42:8029-34.

28. CLSI. Performance Standards for Antimicrobial Disk Susceptibility Tests. 13th ed. Wayne, PA: Clinical and Laboratory Standards Institute; 2018. CLSI standard M02

29. Raheem N, Straus SK. Mechanisms of Action for Antimicrobial Peptides with Multiple Biological Functions. Front Microbiol. 2019;10:2866.

30. Magana M, Pushpanathan M, Santos AL, Leanse L, Fernandez M, Ioannidis A, et al. The value of antimicrobial peptides in the age of resistance. The Lancet Infectious Diseases. 2020.

31. Lei J, Sun L, Huang S, Zhu C, Li P, He J, et al. The antimicrobial peptides and their potential clinical applications. Am J Translational Res. 2019;11:3919.

32. Chen $\mathrm{CH}, \mathrm{Lu}$ TK. Development and challenges of antimicrobial peptides for therapeutic applications. Antibiotics. 2020;9:24.

33. Moghaddam MM, Barjini KA, Ramandi MF, Amani J. Investigation of the antibacterial activity of a short cationic peptide against multidrug-resistant Klebsiella pneumoniae and Salmonella typhimurium strains and its cytotoxicity on eukaryotic cells. World J Microbiol Biotechnol. 2014;30:1533-40.

34. Lozeau LD, Grosha J, Smith IM, Stewart EJ, Camesano TA, Rolle MW. Alginate Affects Bioactivity of Chimeric Collagen Binding LL37 Antimicrobial Peptides Adsorbed to CollagenAlginate Wound Dressings. ACS Biomaterials Science \& Engineering. 2020.

35. Lin Z, Wu T, Wang W, Li B, Wang M, Chen L, et al. Biofunctions of antimicrobial peptide-conjugated alginate/hyaluronic acid/collagen wound dressings promote wound healing of a mixed-bacteria-infected wound. Int $\mathrm{J}$ Biol Macromol. 2019;140:330-42.

36. Shargh EK, Pirestani M, Sadraei J. In vitro toxicity evaluation of short cationic antimicrobial peptide (CM11) on Blastocystis sp. Acta Trop. 2020;204:105384.

37. Azad ZM, Moravej H, Fasihi-Ramandi M, Masjedian F, Nazari R, Mirnejad R, et al. In vitro synergistic effects of a short cationic peptide and clinically used antibiotics against drug-resistant isolates of Brucella melitensis. J Med Microbiol. 2017;66:919-26.

38. Terada D, Kobayashi H, Zhang K, Tiwari A, Yoshikawa C, Hanagata N. Transient charge-masking effect of applied voltage on electrospinning of pure chitosan nanofibers from aqueous solutions. Sci Technol Adv Mater. 2012;13:015003.

39. Ohkawa K, Cha D, Kim H, Nishida A, Yamamoto H. Electrospinning of chitosan. Macromol Rapid Commun. 2004;25:1600-5.

40. Cai Z-X, Mo X-M, Zhang K-H, Fan L-P, Yin A-L, He C-L, et al. Fabrication of chitosan/silk fibroin composite nanofibers for wound-dressing applications. Int J Mol Sci. 2010;11:3529-39.

41. Zhang Q, Zhao Y, Yan S, Yang Y, Zhao H, Li M, et al. Preparation of uniaxial multichannel silk fibroin scaffolds for guiding primary neurons. Acta Biomater. 2012;8:2628-38.

42. Yan S, Han G, Wang Q, Zhang S, You R, Luo Z, et al. Directed assembly of robust and biocompatible silk fibroin/hyaluronic acid composite hydrogels. Compos Part B: Eng. 2019;176:107204.

43. Gu BK, Park SJ, Kim MS, Kang CM, Kim J-I, Kim C-H. Fabrication of sonicated chitosan nanofiber mat with enlarged porosity for use as hemostatic materials. Carbohydr Polym. 2013;97:65-73.

44. Ullah S, Zainol I, Chowdhury SR, Fauzi M. Development of various composition multicomponent chitosan/fish collagen/glycerin 3D porous scaffolds: Effect on morphology, mechanical strength, biostability and cytocompatibility. Int J Biol Macromol. 2018;111:158-68.

45. Sionkowska A, Kaczmarek B, Lewandowska K, Grabska S, Pokrywczyńska M, Kloskowski T, et al. 3D composites based on the blends of chitosan and collagen with the addition of hyaluronic acid. Int J Biol Macromol. 2016;89:442-8.

46. Koosha M, Mirzadeh H. Electrospinning, mechanical properties, and cell behavior study of chitosan/PVA nanofibers. J Biomed Mater Res Part A. 2015;103:3081-93.

47. Xu Z, Shi L, Yang M, Zhang H, Zhu L. Fabrication of a novel blended membrane with chitosan and silk microfibers for wound healing: characterization, in vitro and in vivo studies. J Mater Chem B. 2015;3:3634-42.

48. Luangbudnark W, Viyoch J, Laupattarakasem W, Surakunprapha P, Laupattarakasem P. Properties and Biocompatibility of Chitosan and Silk Fibroin Blend Films for Application in Skin Tissue Engineering. Sci World J. 2012;2012:697201.

49. Choy S, Lam DV, Lee S-M, Hwang DS. Prolonged Biodegradation and Improved Mechanical Stability of Collagen via VaporPhase Ti Stitching for Long-Term Tissue Regeneration. ACS Appl Mater Interfaces. 2019;11:38440-7.

50. Taghipour-Sabzevar V, Sharifi T, Bagheri-Khoulenjani S, Goodarzi V, Kooshki H, Halabian R, et al. Targeted delivery of a short antimicrobial peptide against CD44-overexpressing tumor cells using hyaluronic acid-coated chitosan nanoparticles: An in vitro study. J Nanopart Res. 2020;22:1-16.

51. Bauer AW, Kirby WMM, Sherris JC, Turck M. Antibiotic Susceptibility Testing by a Standardized Single Disk Method. Am J Clin Pathol. 1966;45:493-6.

52. Dart A, Bhave M, Kingshott P. Antimicrobial Peptide-Based Electrospun Fibers for Wound Healing Applications. Macromol Biosci. 2019;19:1800488.

53. Song DW, Kim SH, Kim HH, Lee KH, Ki CS, Park YH. Multibiofunction of antimicrobial peptide-immobilized silk fibroin nanofiber membrane: Implications for wound healing. Acta Biomater. 2016;39:146-55.

54. Chouhan D, Janani G, Chakraborty B, Nandi SK, Mandal BB. Functionalized PVA-silk blended nanofibrous mats promote diabetic wound healing via regulation of extracellular matrix and tissue remodelling. J Tissue Eng Regenerative Med. 2018;12:e1559-e70. 